\title{
CORRESPONDENCE
}

\section{SEPTA AND SUTURES IN JURASSIC AMMONITES}

SIR,-It would be futile to prolong the controversy which arose between the late Dr. Arkell and Dr. Westermann concerning the use of septal form in ammonite classification, and in particular the application of this method to the Middle/Upper Jurassic Stephanocerataceae and Perisphinctaceae. The phylogenetic problems will doubtless be solved in time as evidence accumulates. I would like, however, to make some comments on Dr. Westermann's latest rejoinder (Geol. Mag., Nov,-Dec., 1958).

It is helpful of Dr. Westermann to give us in Section B and figs. 1, 2, and 4 of his paper an English version of the septal classification in his earlier paper (1956, pp. 239-243, figs. 1, 2, and Beilage 1), but this does not provide any further confirmation that the septa can be specially relied upon in phylogenetic classification. According to the explanation of fig. 4 the evolutionary sequence of septum-types corresponds to the ontogenetic sequence; in other words, " recapitulation," embraced uncritically by Hyatt and Buckman, c. 1870-1930, but found to be unworkable and now generally abandoned by ammonitologists, is now assumed to apply to the septa. It is also stated (p. 451) that evolutionary relationships may be inferred from "the similarities and suggested transformation trends of septal types ", although it is not clear how these trends are discovered before the evolutionary pattern itself has been demonstrated. This kind of procedure, like Buckman's assumed cycles of ornament and other characters, seems to me to be one of the most dangerous kinds of palaeontological method, which can rapidly lead to the erection of a whole structure whose validity depends upon unproved assumptions.

Two other ways of using septa to elucidate phylogeny are mentioned (p. 450-1): (1) " by analogous arrangement on the basis of equivalent septal types." I do not understand what this sentence means, unless it merely means grouping like forms together. (2) "from the similarities of the non-adaptive septal characters." The non-adaptive characters are enumerated (p. 447), but their recognition as such depends on acceptance of the Pfaff hypothesis of septal function, which is not universally accepted (Arkell, 1957, p. 243) and cannot be tested. Arbitrary separation into adaptive and non-adaptive characters is merely liable to lessen or obscure the taxonomic value of the septum or suture-line as a whole.

One particular example may be examined. With regard to the distinction between the subfamilies Otoitinae and Normannitinae, which he places in different families, Dr. Westermann writes that the differences between the suture-lines " correspond with the abullate and aplanulate septal main-types which rank at the family level "(p. 451). The two septal types are those in the " heterochrone" series which are found in sphaerocone and serpenticone shell-forms respectively. According to Pfaff's theory, accepted by Westermann, changes in the septal type must follow automatically on changes in shell-form. One may choose to regard the difference between the shell-forms as the basis of a distinction at family level, but the correlated septal differences cannot add further weight to the distinction. In this case Dr. Arkell believed that the difference between Otoites and Normannites, which is principally one of shell-form, was of no more than gemeric importance.

In the case of the origin of the Parkinsonidae (p. 454), does not Dr. Westermann's acceptance of the descent of Parkinsonia, with an " aschizolate" septum, from " Infraparkinsonia", with a "euplanulate" one, make nonsense of his own diagram (fig. 4) showing " transformation of septa ... in ontogeny and evolution"? Reference to this diagram shows that these two types occur in different series of "transformations".

In conclusion, it seems to me that Dr. Westermann has not answered Dr. Arkell's principal objection to his method: namely that septa can often be demonstrated to be unreliable, and, more important, that there is no 
substitute for an evaluation of all characters, taken in conjunction with stratigraphical evidence, in making a classification. He has repeated what he has said in previous works, but he has not advanced any new evidence to convince more conservative palaeontologists that septa, any more than any other single character, are the kẻy to ammonite phylogeny.

D. T. Donovan.

\section{REFERENCES}

ARKELL, W. J., 1957. Sutures and septa in Jurassic ammonite systematics. Geol. Mag., xciv, 235-248.

Westermann, G. E. G., 1956. Phylogenie der Stephanocerataceae und Perisphinctaceae des Dogger. Neues Jb. Geol. u. Paläont., Abh. ciii, 233-279.

1958. The significance of septa and sutures in Jurassic ammonite systematics. Geol. Mag., xcv, 441-455.

\section{ULTRABASIC PILLOW LAVAS FROM CYPRUS}

SIR,--Mr. D. W. Bishopp, who initiated the Cyprus Geological Survey in September, 1950, published the following papers on the Troodos Massif :-

“The Troodos Massif," Nature, vol. 169, No. 4299, 22nd March, 1952.

"Some new features of the Geology of Cyprus," XIX Intern. Geol. Cong., Algiers, 1952.

Much of the preliminary reconnaissance work in the Troodos area, as well as some detailed mapping, was undertaken by Mr. Bishopp. I regret therefore that in the brief history of the Cyprus Geological Survey, given in the introduction of my paper, Mr. Bishopp's contribution was not sufficiently acknowledged and also his two papers were not given as references.

The bulk of Mr. Bishopp's letter concerns the Diabase Formation and as my colleagues Mr. L. M. Bear and Mr. R. A. M. Wilson are more familiar with these rocks I prefer to leave any description and discussion to them. Memoirs by Bear and Wilson, based on detailed mapping of parts of the Troodos Massif, are due to be published in the near future; both put forward evidence in favour of an intrusive origin for most of the Diabase Formation.

Geological Survey Dept.,

I. G. GASS.

NICOSIA,

CyPRUs.

15th January, 1959.

\section{THE VISCOSITY OF ROCK-GLASS OF GRANITIC COMPOSITION UNDER VARIOUS PHYSICAL CONDITIONS: A CORRECTION AND AN ADDENDUM}

SIR,-In a recent paper on "Granite: some tectonic, petrological and physico-chemical aspects," published in this Magazine (1958, pp. 378-396) I referred on p. 393 to Saucier's determination of the viscosity of retinite (a variety of pitchstone) under pressure of gaseous water. Saucier found the viscosity to be $10^{7}$ poises at $980^{\circ} \mathrm{C}$. with a pressure of gaseous water of 160 bars. Through some error this pressure is wrongly recorded in my paper as 750 bars; the mistake does not alter the conclusions.

Dr. Saucier-has kindly drawn my attention to further important investigations of the viscosity of rétinite by his colleague Sabatier (1956). The results of these experiments are of particular interest because they provide a measure of the effects both of increasing pressure of gaseous water and of increasing temperature in lowering the viscosity of natural pitchstone. The following three series of viscosity determinations were made by Sabatier: (1) Nine determinations made at atmospheric pressure under dry conditions showed 